\title{
Antioxidant and pro-oxidant factors in oregano and rosemary gourmet olive oils
}

\author{
By Mayada Damechki ${ }^{1}$, Sofia Sotiropoulou ${ }^{2}$ and Maria Tsimidou ${ }^{2^{*}}$ \\ 1 Mediterranean Agronomic Institute of Chania (MAICH), Alsillion Agrokipiou, \\ Chania, 73100 Crete, Greece. \\ 2 Laboratory of Food Chemistry and Technology, Faculty of Chemistry, Aristotle University \\ of Thessaloniki, 54006 Thessaloniki, Greece. E-mail: tsimidou@chem.auth.gr
}

\section{RESUMEN}

Factores antioxidantes y prooxidantes en aceite de oliva con aroma a orégano y romero.

El estudio fue realizado para examinar la presencia de antioxidantes y pro-oxidantes en aceites de oliva con aroma a orégano y romero. El material vegetal seco y molido se añade al aceite de oliva en proporción ( $5 \%$ w/w) durante 24,48 y 72 horas y posteriormente se elimina por filtración. Todas las preparaciones se encontraron aceptables usando un panel de catadores. El contenido de fenoles polares totales aumentó 3,5 y 1,7 veces, en aceites con aroma a orégano y romero, con respecto al de las muestras control. Un enriquecimiento cualitativo de la fracción metanol:agua del aceite de oliva, con compuestos fenólicos de las hierbas, se encontró usando HPLC. No se detectó ácido rosmarinico en los aceites estudiados. El ácido vanillinico solo se encontró en los aceites con sabor a romero. La presencia de flavonoides se evaluó usando TLC. El contenido de $\alpha$-tocoferol del aceite matriz no cambió tras la infusión con hierbas. En aceites con aroma a orégano se encontró un aumento significativo en el contenido de feofitina, $\alpha, \beta$-caroteno y luteina. La estabilidad oxidativa de los aceites fue mayor que las del control usando el test Rancimat. En foto-oxidación, los aceites con sabor a orégano fueron menos estables que los de romero. El contenido en clorofilas totales puede ser un factor crítico para la vida media de estas preparaciones. Un etiquetado que sugiera el evitar la luz puede ser aconsejable para un uso doméstico seguro.

PALABRAS-CLAVE: Aceite de oliva - Antioxidante - Orégano-Pro-oxidante - Romero.

\section{SUMMARY}

Antioxidant and pro-oxidant factors in oregano and rosemary gourmet olive oils.

The study was carried out to examine the presence of antioxidants and pro-oxidants in oregano and rosemary gourmet oils. Dry, ground plant material $(5 \% \mathrm{w} / \mathrm{w})$ was infused to olive oil for 24,48 and 72 hours and then it was removed by filtration. All preparations were found acceptable using a panel test. The total polar phenol content increased 3.5 and 1.7 times in oregano and rosemary gourmet oils with respect to that of the control sample. A qualitative enrichment of the methanol:water fraction of olive oil with phenolic compounds from herbs were found using HPLC. No rosmarinic acid was detected in the gourmet oils. Vanillic acid was only found in the rosemary gourmet oil. The presence of flavonoids was assessed using TLC. $\alpha$-Tocopherol content of the oil matrix was not changed after herb infusion. A significant increase was found in pheophytin, $\alpha, \beta$-carotene and lutein content of oregano flavoured oils. The oxidative stability of gourmet oils was greater to that of the control using the Rancimat test. In photo-oxidation, oregano flavoured oil was less stable than the rosemary one. Total chlorophyll content may be a critical factor for the shelf life of these preparations. Suitable labelling suggesting avoidance of light may be useful for a safe domestic use.

KEY-WORDS: Antioxidant - Olive oil - Oregano - Pro-oxidant - Rosemary.

\section{INTRODUCTION}

The last few years some new products based on olive oil appeared in the market. Some of them are olive oils flavoured with herbs or spices. Dry herbs or their extracts are used in oils or lipid-containing foods to retard oxidative deterioration (Hermann, 1981; Namiki, 1990; Nakatani, 1994; Madsen and Bertelsen, 1995; Madsen et al., 1998). In previous studies it was shown that oregano and rosemary gourmet olive oils exhibited extended shelf life in the dark possibly due to antioxidants extracted from the plant material (Antoun and Tsimidou, 1997). The most important phenolic antioxidants reported in oregano are rosmarinic acid and other caffeic acid derivatives (Kikuzaki and Nakatani, 1989), apigenin, eridictyol, dihydrokaempherol and dihydroquercetin (Vekiari et al., 1993), $\gamma$-tocopherol (Lagouri and Boskou, 1996) as well as the constituents of essential oil, thymol and carvacrol (Lagouri et al., 1993). The antioxidant effect of rosemary is related to the presence of carnosic acid, carnosol and rosmarinic acid (Cuvelier et al., 1996). Carnosic acid and its derivatives are potent antioxidants (Huang et al., 1996; Hopia et al., 1996). Other compounds identified in rosemary extracts are rosmaridiphenol and rosemariquinone or more hydrophilic compounds, such as luteolin and derivatives (Stoick et al., 1991; Okamura et al., 1994). The gourmet oils were also well admitted by the consumers for flavour and taste (Antoun and Tsimidou, 1998).

Products such as gourmet olive oils, representative articles of the Mediterranean cuisine, attract the interest of the consume, hence, more should be known about their quality characteristics. The study aims at examining the presence of certain antioxidants and pro-oxidants in gourmet oils, which may affect not only the shelf life under common 
storage conditions but also the potential functional properties of oregano and rosemary gourmet oils.

\section{EXPERIMENTAL}

\subsection{Samples}

As control sample a commercial product of "olive oil» grade was used. Dry oregano leaves (Origanum vulgare L.ssp. hirtum) from plants cultivated in the botanical garden of the Mediterranean Agronomic Institute of Chania, Crete, Greece (MAICh) were ground to pass a $400 \mu \mathrm{m}$ sieve. A commercial packed sample of dry rosemary leaves (Rosemarinus officinalis, L.) purchased from the spice market in Chania was also ground and sieved, accordingly. The ground herbs were put in jars, purged with nitrogen and stored in a cool dark place until use.

\subsection{Reagents and standards}

All reagents and solvents of suitable grade were from various suppliers. dl- $\alpha$-tocopherol standard ( $99 \%$ for biochemistry) and caffeic acid were from Merck (Darmstadt, Germany). Gallic, protocatechuic, vanillic, $p$-coumaric, ferulic, o-coumaric, $p$-hydroxybenzoic, p-hydroxyphenylacetic, 4-hydroxy-3-methoxyphenylacetic, syringic, 3,4-dihydroxyphenyl acetic acids, quercetin and rutin were from Sigma Co. (St Louis, MO). Tyrosol (98\%) was from Aldrich Co. (Milwaukee, WI). Rosmarinic acid (HPLC, 99\%) was from Czech Moravian and Slovak Chemicals (Oxford, England).

\subsection{Apparatus}

A Hewlett Packard Vectra 486/33U, 8452A UV-Vis spectrophotometer (Palo Alto, CA) was used for absorbance measurements. Measurements were taken in $1 \mathrm{~cm}$ glass or quartz cells. Determination of tocopherols and pigments was performed with a liquid chromatograph Marathon IV (Rigas Labs, Thessaloniki, Greece) equipped with a Shimadzu UV-Vis SPD-10AV detector (Kyoto, Japan) connected in series with a diode array Linear UVIS-206 Multiple Wavelength detector (Linear Instr. Fermont, CA). The data from the detectors were stored and processed with the chromatographic software EZChrom (Sci. Software Inc., San Ramon, CA). Separation of phenols was performed on a Hewlett Packard liquid chromatograph (Model 1090 Series II) with a quaternary solvent delivery system and auto-injector, equipped with a diode array detector. The Hewlett Packard Chemstation 3D software package was used for data acquisition and analysis. Oxidative stability of oils was determined using a Rancimat 617 apparatus (Metrohm, Herisau, Basel Switzerland).

\subsection{Preparation and quality characteristics of gourmet olive oils}

Ground herbs (5\% w/w) were added to olive oil and were mixed thoroughly by shaking for 24, 48 and 72 hours at $40{ }^{\circ} \mathrm{C}$ in the dark. After the infusion period the plant material was removed by filtration through paper filter. Quality parameters were determined in the filtered samples. Peroxide values and coefficients of specific extinction $\left(\mathrm{K}_{232}, \mathrm{~K}_{270}\right)$ were determined according to established methods (EC, 1991). Chlorophyll pigments, expressed as mg pheophytin $\alpha$ per $\mathrm{kg}$ of oil, were measured according to Pokorny et al. (1995). Total polar phenols were extracted with methanol: water, 60:40, v/v and expressed as mg caffeic acid per $\mathrm{kg}$ of oil (Gutfinger, 1981). The repeatability of each method was checked (coefficient of variation less than $5 \%$ in each case) and all measurements were subsequently performed at least in duplicate.

\subsection{HPLC determination of polar phenolic compounds, tocopherols and pigments}

Chromatographic separation of the polar phenolic compounds was achieved on a Lichrospher 100RP-18, $5 \mu \mathrm{m}$ column ( $250 \times 4 \mathrm{~mm}$ i.d.) (Hewlett Packard) using a gradient method developed by Tsimidou et al. (1996). Tocopherols and pigments of samples were separated on a $250 \times 4 \mathrm{~mm}$ i.d. LiChrospher-Si 60, $5 \mu \mathrm{m}$, column (Analysentechnik, Mainz, Germany) according to Psomiadou and Tsimidou (1998).

\subsection{Thin layer chromatography (TLC) of phenolic compounds}

Silica plates $(0.25 \mathrm{~mm})$ were used for the separation of phenolic compounds and $\mathrm{CH}_{3} \mathrm{COO}$ Et- $\mathrm{MeOH}-\mathrm{H}_{2} \mathrm{O}, 77: 13: 10, \mathrm{v} / \mathrm{v} / \mathrm{v}$ as the developing system (Montedoro et al., 1992). The plates were then sprayed with a) $\mathrm{FeCl}_{3}(2 \%$ in ethanol) which produces coloured spots with all phenolic compounds and b) $\mathrm{AlCl}_{3}(1 \%$ in ethanol) which gives a yellow fluorescence with 5-hydroxy- flavonoids having a carbonyl group at C-4 (Schulz and Hermann, 1980). Rf values of spots from the polar fraction were compared to those of standards.

\subsection{Stability studies}

Oil Stability Indices (OSI) of the samples were determined using the Rancimat apparatus at $120^{\circ} \mathrm{C}$ at an airflow of $20 \mathrm{l} / \mathrm{h}$ (AOCS, 1993). Protection factors (PF) were calculated according to the equation: $\mathrm{PF}=$ sample induction time versus control induction time. Photo-oxidation studies were carried out in a light chamber (GRW-500D, CDR (Crisagis, 
Athens, Greece). Oil samples $(5 \pm 0.001 \mathrm{~g})$ were poured into $15 \mathrm{ml}$ transparent glass bottles. The bottles were placed closed in the centre of a white enamel painted metallic shelf. The distance of the samples from the fluorescence lamp was $30 \mathrm{~cm}$, and between the samples adequate space was left to ensure equalised exposure. The temperature of the chamber was kept at $25 \pm 1{ }^{\circ} \mathrm{C}$ and the light intensity at sample level was 12100 lux. Peroxide value, total polar phenol content and total chlorophyll content of the exposed samples was measured periodically.

\subsection{Consumer acceptability tests}

Sensory assessment (Lawless and Heymann, 1998) of the gourmet oil samples was carried out by a panel consisting of 18 untrained members randomly selected from a pool of students and staff at MAICh. The samples were labelled and evaluated in triplicate within three (3) consecutive days for each plant preparation. The samples were presented on small bread slices. The panellists were asked to smell, taste and then rank them in order of their degree of odour and flavour acceptability. The tasters used an acceptability scale from 0 to 5 with the following designations: no odour and flavour, very weak, weak, medium strong, strong and very strong. Overall grading for each sample was the mean of 54 scores (18 evaluations in triplicate). All panel scores were converted to ranked data prior to statistical analysis. Analysis of variance was performed on ranked panel scores using a Friedman two-way ANOVA model to analyse all data. Significant differences among means were determined by Duncan's Multiple Range test, T-test and Tukey's Studentized Range (HSD) test (Steel and Torrie, 1960; Montgomery, 1984). The level of statistical significance was 0.05 in all cases. A statistical package (SPSS for Windows release 6.0 -Jun 17, 1993-copyright SPSS Inc. 1989-1993, licensed to academic computing services 708722) was used for data analysis.

\section{RESULTS AND DISCUSSION}

\subsection{Effect of infusion period to the sensorial characteristics of gourmet olive oils}

Consumer acceptability tests were conducted to collect data about the effect of infusion period to the sensorial characteristics of gourmet products. Data from 18 questionnaires were analyzed to receive information about this new product. Half of the panelists were below the age of 30 years old and most of them were accustomed to Mediterranean cuisine. Using the ANOVA and the Friedman two-way ANOVA for the control and gourmet oils produced at three different infusion periods $(24,48$
Table I

\section{Comparison of mean scores among the gourmet olive oils using the T-test (LSD), Duncan's Multiple Range test and Tukey's Studentized Range (HSD) test}

\begin{tabular}{cccc}
\hline Treatment & Mean score & Treatment & Mean score \\
\hline Control & $3.04^{\star}$ & Control & $2.91^{*}$ \\
+ oregano, 24h & $4.15^{\star *}$ & + rosemary, 24h & $3.74^{\star *}$ \\
+ oregano, 48h & $4.26^{\star *}$ & + rosemary, 48h & $3.89^{\star *}$ \\
+ oregano, 72h & $4.35^{\star *}$ & + rosemary, 72h & $3.96^{* *}$ \\
\hline
\end{tabular}

Means with the same number of asterisks are not significantly different at 0.05 level.

and 72 hours) it was found that the addition of the plant material (treatment) had a highly significant effect on the flavour and taste of olive oil. The Friedman two-way ANOVA test showed no significant differences among the replications of the same sample. The means of the triplicate scores for each speciality were compared using a Duncan's Multiple Range test, T-test (LSD) and Tukey's Studentized Range test (HSD) (Table I). Most panellists judged the odour and flavour of the samples as medium strong to strong. Infusion time was not found to affect significantly the sensorial characteristics of both oregano and rosemary flavoured olive oils. All samples were considered suitable for further examination.

\subsection{Effect of infusion period to the quality characteristics of gourmet olive oils}

The effect of infusion period to peroxide value, UV absorbance, total polar phenol content, $\alpha$-tocopherol content and total chlorophyll content was then studied. Data is shown in Table II. No marked increase was observed for peroxide values or absorbance at 232 and $270 \mathrm{~nm}$ for both oregano and rosemary gourmet olive oils at all experimental conditions in comparison to initial values of the control sample. No pro-oxidant effect was observed from the infusion. Total polar phenol content in oregano flavoured oils increased about 3.5 times in comparison with that of the control. For the rosemary flavoured oil an increase of 1.7 times was observed. Considering that total phenols correlate well with oxidative stability of olive oil (Tsimidou, 1998) the increased amount of them is expected to affect positively the stability of the oil matrix. The content of the major olive oil tocopherol, $\alpha$-tocopherol, remained at the same levels (Table II). The increase observed for total chlorophyll content, as measured spectrometrically, was in particular high in oregano flavoured olive oil, which suggests a pro-oxidant role of these pigments under light exposure. 
Table II

Quality characteristics of gourmet olive oils

\begin{tabular}{|c|c|c|c|c|c|c|c|}
\hline \multirow{3}{*}{ Characteristic } & \multicolumn{7}{|c|}{ Herb infusion period (hours) } \\
\hline & \multirow{2}{*}{$\frac{0}{\text { Control }}$} & \multicolumn{2}{|c|}{24} & \multicolumn{2}{|c|}{48} & \multicolumn{2}{|c|}{72} \\
\hline & & Oregano & Rosemary & Oregano & Rosemary & Oregano & Rosemary \\
\hline PV & 7.30 & 7.9 & 8.0 & 8.0 & 8.1 & 9.2 & 8.8 \\
\hline $\mathrm{K}_{232}$ & 2.30 & 2.55 & 2.77 & 2.54 & 2.88 & 2.40 & 2.81 \\
\hline $\mathrm{K}_{270}$ & 0.67 & 0.95 & 0.94 & 0.95 & 0.91 & 0.90 & 0.93 \\
\hline Total polar phenol content ${ }^{(a)}$ & 58.00 & 168.5 & 88.0 & 177.0 & 98.0 & 191.5 & 90.0 \\
\hline$\alpha$-Tocopherol content ${ }^{(b)}$ & 194.00 & 170.0 & 171.0 & 145.0 & 181.0 & 160.0 & 163.0 \\
\hline Chlorophyll content $^{\odot}$ & 13.00 & 31.6 & 22.8 & 33.2 & 23.5 & 35.2 & 24.1 \\
\hline
\end{tabular}

$(\mathrm{a})=\mathrm{mg}$ caffeic $\mathrm{acid} / \mathrm{kg}$ oil; ( $\mathrm{b}=\mathrm{mg} / \mathrm{kg}$ oil); (c) = mg pheophytin $\alpha / \mathrm{kg}$ oil.

\subsection{Effect of infusion period to the chromatographic profile of polar phenolic compounds}

Though transfer of potent antioxidants from herbs to the oil matrix is partial, gourmet oils appear to be enriched in phenols extracted with methanol: water mixtures. The impact of recent findings on the health benefits of polar phenols is very important for the agri-food industry and their use for seasoning food coincides with the trend for reducing salt in the diet. Standardisation and careful control of the herbs used for the preparation of similar commercial products is therefore important.

The presence of individual phenols was examined using RP-HPLC. The profile of the polar fraction of gourmet oils produced under the optimised chromatographic conditions for olive oil phenol separation was enriched with new compounds. The number of new compounds absorbed at $278 \mathrm{~nm}$ was greater in the case of rosemary speciality in accordance with the findings reported by Cuvelier et al. (1996). This is illustrated in Fig.1 for rosemary

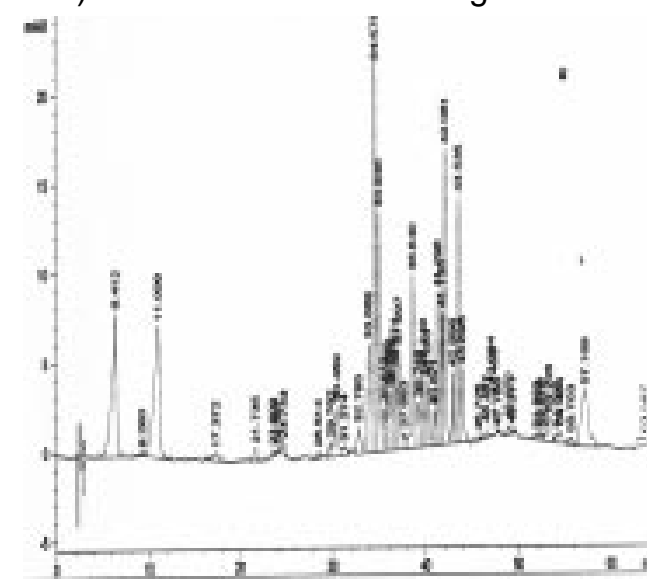

flavoured oil after $48 \mathrm{~h}$ infusion. These peaks recorded at 256, 278, 295 and $325 \mathrm{~nm}$ may be attributed to phenolic compounds. Identification based on relative retention time to tyrosol, spectral characteristics and spiking with the available standards was difficult. The presence of vanillic acid in rosemary oil was verified using these means. No rosmarinic acid was detected. An attempt to identify characteristic compounds such as quercetin or rosmarinic acid was also made using TLC chromatography. Some flavonoids, not present in the control sample, were detected after visualisation with $\mathrm{AlCl}_{3}$. These flavonoids belonging to three different groups according to $\mathrm{Rf}$ values could be another stability factor for the herb specialities.

\subsection{Effect of infusion period to the content of pigments of gourmet olive oils}

Addition of plant material to food products is in general limited not only because they impart characteristic flavour but also due to colour changes.

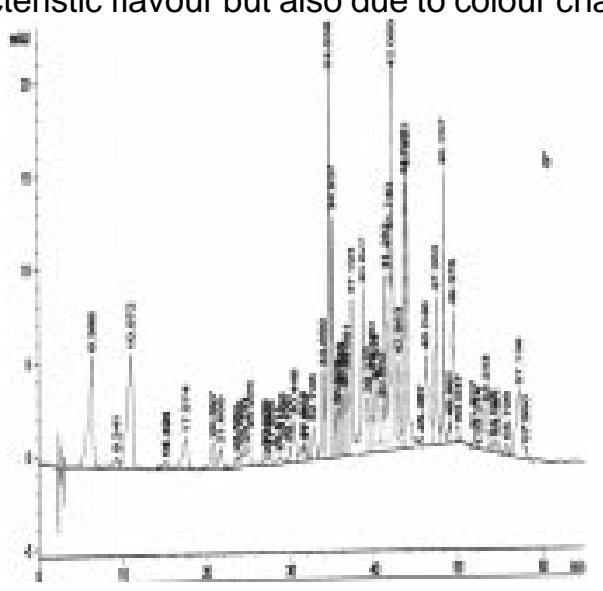

RP-HPLC profile of the polar phenolic compounds at $278 \mathrm{~nm}$ : control sample, (a) and rosemary flavoured oil after $48 \mathrm{~h}$ infusion, (b). Chromatographic details in 2.5 . 
Table III

Major chlorophyll and carotenoid pigments of gourmet olive oils

\begin{tabular}{|c|c|c|c|c|c|c|c|}
\hline \multirow{3}{*}{$\begin{array}{l}\text { Pigment } \\
\text { content }\end{array}$} & \multicolumn{7}{|c|}{ Herb infusion period (hours) } \\
\hline & \multirow{2}{*}{$\frac{0}{\text { Control }}$} & \multicolumn{2}{|c|}{24} & \multicolumn{2}{|c|}{48} & \multicolumn{2}{|c|}{72} \\
\hline & & Oregano & Rosemary & Oregano & Rosemary & Oregano & Rosemary \\
\hline Pheophytin $\alpha^{1}$ & 11.5 & 58.1 & 13.1 & 63.2 & 14.3 & 66.3 & 14.7 \\
\hline$\beta$-Carotene ${ }^{2}$ & 1.1 & 3.5 & 1.1 & 5.3 & 1.6 & 3.3 & 1.5 \\
\hline Lutein $^{2}$ & 0.5 & 2.4 & 0.8 & 5.0 & 0.8 & 3.8 & 0.8 \\
\hline
\end{tabular}

${ }^{1}$, mg / $\mathrm{kg}$ oil; ${ }^{2}$, carotenoid pigments were expressed as $\mathrm{mg}$-carotene $/ \mathrm{kg}$ oil.

The increase of total chlorophyll content observed in the two specialities affected the green hues of olive oil. The occurrence and levels of individual pigments were examined using HPLC. The results are presented in Table III. Examination of changes in individual pigments indicated the presence of pheophytin $\alpha$ and related pigments. The increase was significant in oregano ( 5 fold) flavoured olive oil whereas in the rosemary one the increase was slight. The role of chlorophyll pigments in the keeping quality of edible oils and, especially, of virgin olive oil has not been extensively investigated. Their action as photosensitisers defines their potential role under light exposure, but not during autoxidation. Pheophytin $\alpha$ presents an antioxidant role in the dark, which increases with its levels (Schwartz and Lorenzo, 1990). The increased content of pheophytin $\alpha$ in oregano oil is thus expected to contribute positively to its stability in the dark whereas the opposite should be expected under light.

Similar observation can be made for changes in the carotenoid content of oregano and rosemary flavoured oils. A 3-5 fold increase in $\beta$-carotene and lutein content was found for oregano flavoured oil in contrast to the negligible increase observed in the rosemary one (table III). Carotenoids as singlet oxygen quenchers protect oils from photo-oxidation whereas their role in autoxidation is associated with the presence of tocopherols (Perrin, 1992; Servili et al., 1996). The increased amount of carotenoids should, consequently, be beneficial for oregano specialities either under light exposure or during storage in the dark.

\subsection{Stability of gourmet olive oils}

The above results indicated the necessity to assess the extent to which the above changes in phenol and pigment content affected the oxidative stability under different conditions.

Stability tests using the Rancimat apparatus showed a considerable increase in the shelf life of olive oil in the presence of the plant material.
Induction periods and the calculated protection factors are shown in Table IV. In all cases, the induction periods were greater for the gourmet products than for the control sample. Induction periods did not alter with increased infusion period. Induction periods were greater for rosemary flavoured oils compared to those for the oregano ones. Protection factors indicate the strong antioxidant activity of the phenolic components, which had been transferred from the herbs to the oil during the infusion period.

The resistance to photo-oxidation was then tested for gourmet oils prepared after $48 \mathrm{~h}$ agitation. The samples were exposed to light, at 12100 lux for 6,18 and 24 hours. The oxidation process was followed by periodic measurement of peroxide values, total polar phenol and chlorophyll content. As indicated in Fig. 2a, peroxide value changes were higher for oregano flavoured oil compared with those for rosemary or for the control sample. As expected, for primary antioxidants, total phenol content was not affected by light, for all the samples throughout the exposure period, in contrast to the fast degradation of total chlorophylls in all samples (Fig. 2b). The pleasant green colour of the samples disappeared after 18 hours of exposure to light. It may be argued that total chlorophylls content is a critical factor for the shelf life of these preparations both in the retail

Table IV

Induction periods and calculated protection factors (PF) for oil samples

\begin{tabular}{lcc}
\hline \multicolumn{1}{c}{ Oils } & $\begin{array}{c}\text { Induction period } \\
\text { (hours) }\end{array}$ & Protection factor PF \\
\hline Control & 4.37 & 1.00 \\
+5\% Rosemary, 24h & 9.03 & 2.10 \\
+5\% Rosemary, 48h & 8.72 & 2.00 \\
+5\% Rosemary, 72h & 8.32 & 1.90 \\
+5\% Oregano, 24h & 6.73 & 1.50 \\
+5\% Oregano, 48h & 6.97 & 1.60 \\
$+5 \%$ Oregano, 72h & 6.93 & 1.50 \\
\hline
\end{tabular}



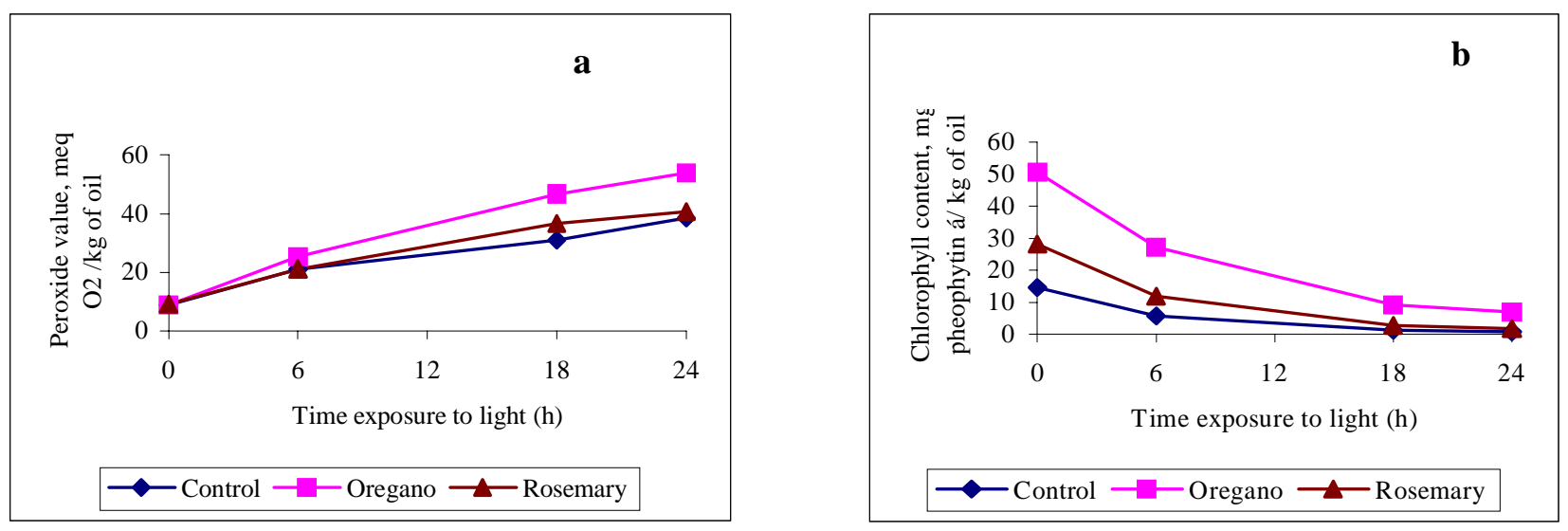

Figure 2

Changes in peroxide value (a), and total chlorophyll content (b) of the control, oregano and rosemary flavoured oils during storage at 12100 lux. Infusion period 48 hours.

market and in domestic storage. Suitable labelling suggesting avoidance of light may be useful for a safe domestic use.

\section{ACKNOWLEDGEMENTS}

M. Damechki acknowledges the receipt of a fellowship from MAICh during her MSc studies. The authors are grateful to all panellists for kindly participating in the tests. The research was partially financed by the General Secretariat for Research and Technology, Greek Ministry of Development (Programme EPET II, 97DIATRO-29 «Study of the presence and bioavailability of phenolic antioxidants in food articles of the Mediterranean diet»).

\section{BIBLIOGRAPHY}

Antoun, N. y Tsimidou, M. (1997). Gourmet olive oils: stability and consumer acceptability studies. Food Research International, 30, 131-136.

Antoun, N. y Tsimidou, M. (1998). Olive oil herb and spice specialities : preconceived ideas of potential consumers about their nutritional and sensorial attributes. Olivae, 71, 56-62.

AOCS Official Methods. (1993). Oil Stability Index (OSI). Cd12b-92.

Cuvelier, M.E., Richard, H. y Berset, C. (1996). Antioxidative activity and phenolic composition of pilot-plant and commercial extracts of sage and rosemary. J. Am. Oil Chem. Soc. 73, 645-652.

EC Regulation no. 2568/1.7.91. (1991). On the characteristics of olive oils and kernel olive oils and on their methods of analysis. L248, 5.9.

Gutfinger, T. (1981). Polyphenols in olive oils. J. Am. Oil Chem. Soc. 58, 966-968.

Hermann, V.K. (1981). Über die antioxidative wirkung von gewürzen. Deutsche Lebensmittel Rundschau, 77, 134-138.

Hopia, A.I., Huang, S.H., Schwarz, K., German, T.B., Frankel, E.N. y Huang, S.W. (1996). Effect of different lipid systems on anitoxidant activity of rosemary constituents carnosol and carnosic acid with and without alpha-tocopherol. J. Agric. Food Chem. 44, 2030-2036.

Huang, S-W., Frankel, E.N., Schwarz, K., Aeshbach, R. y German, J.B. (1996). Antioxidant activity of carnosic acid and methyl carnosate in bulk oils and oil-in-water emulsions. J. Agric. Food Chem. 44, 2951-2956.

Kikuzaki, H. y Nakatani, N. (1989). Structure of a new antioxidative phenolic acid from Oregano (Origanum vulgare L.). J. Agric. Biol. Chem. 53, 519-524.

Lagouri, V., Blekas, G., Tsimidou, M., Kokkini, S. y Boskou, D. (1993). Composition and antioxidant activity of essential oils from Oregano plants grown wild in Greece. Z. Lebensm Unters Forsch. 197, 20-23.

Lagouri, V. y Boskou, D. (1996). Nutrient antioxidants in oregano. International Journal of Food Science and Nutrition, 47, 493-497.

Lawless, H.T. y Heymann, H. (1998). Sensory evaluation of food, principles and practices. Chapman \& Hall ed. New York.

Madsen, H.L. y Bertelsen, G. (1995). Spices as antioxidants. Trends in Food Sci. \& Techn. 6, 271-276.

Madsen, H.L., Serensen, B., Skibsted, L.H. y Bertelsen, G. (1998). The antioxidative activity of summer savory (Satureja hortensis L.) and rosemary (Rosmarinus officinalis $L$.) in dressing stored exposed to light or in darkness. Food Chem. 63, 173-180.

Montedoro, G.F., Servili, M., Baldioli, M. y Miniati, E. (1992). Simple and hydrolyzable phenolic compounds in olive oil: Note 1. Their extraction, separation, and quantitative and semiquantitative separation and evaluation by HPLC. J. Agric. Food Chem. 40, 1571-1576.

Montgomery, D.C. (1984). Design and analysis of experiments, $2^{\text {nd }}$ Ed., John Willey Book Co., New York.

Nakatani, N. (1994). Antioxidative and antimicrobial constituents of herbs and spices in Spices, Herbs and Edible Fungi, p. 251-271. Charalambous, G. (Ed.), Elsevier Science B.V.

Namiki, M. (1990). Antioxidants/Antimutagens in Food. CRC Crit. Rev. Food Sci. 29, 273-300.

Okamura, N., Fujimoto, Y., Kuwabara, S. y Yagi, A. (1994). High performance liquid chromatographic determination of carnosic acid and carnosol in Rosmarinus officinalis and Salvia officinalis. $J$. Chromatogr. 679, 381-386. 
Perrin, J. L. (1992). Minor components and natural antioxidants of olives and olive oils. Rev. Franç. Corps Gras, 39, 25-32.

Pokorn, J., Kalinova, L. y Dysseler, P. (1995). Determination of chlorophyll pigments in crude vegetable oils. Pure \& Appl. Chem. 67, 1781-1787.

Psomiadou, E. y Tsimidou, M. (1998). Simultaneous HPLC determination of tocopherols, carotenoids and chlorophylls for monitoring their effect on virgin olive oil oxidation. J. Agric. Food Chem. 46, 5132-5138.

Schulz, J. M. y Hermann, K. (1980). Analysis of hydrobenzoic and hydroxycinnamic acids in plant material I. Sample preparation and thin layer chromatography. J. Chromatogr. 195, 85-94.

Schwartz, S.J. y Lorenzo, T.V. (1990). Chlorophylls in foods. CRC Crit. Rev. Food Sci. Nutr. 29, 1-17.

Servili, M., Baldioli, M., Miniati, E. y Montedoro, G.F. (1996). Antioxidant activity of new phenolic compounds extracted from virgin olive oil and their interaction with a-tocopherol and $\beta$-carotene. Riv It. Sostanze Grasse, 73,55-59.
Steel, G. y Torrie, J. (1960). Principles and procedures of statistics, McGraw-Hill, New York.

Stoick, S.M., Gray, J.I., Booren, A.M. y Buckley, D.J. (1991). Oxidative stability of restructured beef steaks processed with oleoresin rosemary, tertiary butyl hydroquinone and sodium tripolyphosphate. J. Food Sci. 56, 597-600.

Tsimidou, M., Litridou, M., Boskou, D., Pappa-Louisi, A., Kotsifaki, F. y Petrakis, C. (1996). On the determination of minor phenolic acids of virgin olive oil by RP-HPLC. Grasas y Aceites, 47, 151-157.

Tsimidou, M. (1998). Polyphenols and quality of virgin olive oil in retrospect. Ital. J. Food Sci. 10, 99-116.

Vekiari, S.A., Oreopoulou, V., Tzia, C. y Thomopoulos, C.D. (1993). Oregano flavonoids as lipid antioxidants. $j$. Am. Oil Chem. Soc. 70, 483-487.

Recibido: Junio 2000 Aceptado: Enero 2001 